\title{
Mechanical advantage in the size-weight illusion*
}

\author{
CHRISTOPHER M. DAVIS \\ Simon Fraser University, Bumaby, British Columbia, Canada
}

\begin{abstract}
When a hand-held object is lifted by wrist flexion, the lifting system composed of muscles, bones, and the object lifted constitutes a third-class lever. Therefore, objects require greater lifting force as they are supported further distally. The small can of the DeMoors size-weight illusion cans is usually supported further distally than the large one, possibly influencing their relative perceived weight. When Ss are required to lift the small can through a shorter lever than the large one, there is a significant shift of judgments toward a reversal of the SWI in a paired-comparison situation. It is concluded that mechanical advantage does influence weight judgments and that biomechanical factors should be considered whenever weight judgments are made.
\end{abstract}

Biomechanics may play a role in the perceived weight of lifted objects in general and in the size-weight illusion in particular.

When a hand-held object is lifted by wrist flexion, the lifting muscles act on the object through a system of levers comprising the hand and fingers. The lifting system (the muscles, bones, and the weight lifted) consistute a third-class lever, that is, one in which both the input force (lifting muscles) and the output force (the object) are on the same side of the fulcrum and the distance from the fulcrum to the input force is less than that from the fulcrum to the output force. ${ }^{1}$ The mechanical advantage of an ideal lever system of this sort is always less than unity and is equal to the ratio of the shorter length to the longer $\left(M_{t}=l_{i} l_{o}\right)$ (Morgan, 1963, pp. 218). While $l_{i}$, the distance from the wrist to the muscle attachment, remains constant, $l_{o}$, the distance from the fulcrum varies as objects are grasped differently, i.e., by the fingertipe or near the palm of the hand. As that distance varies, the mechanical advantage changes and, consequently, the force required to lift objects of uniform weight, so that an object is easier to lift when supported near the palm than when supported by the fingertips.

In a weight-comparison situation, where objects are serially lifted for the purpose of comparing their relative weights, differences in perceived weight could well be the result of having hoisted the objects through unequal levers. One of the earliest explanations of comparative weight judgments held that the comparison was between the ease with which objects could be lifted when approximately the same force was applied (Müller \& Schumann, 1889). It follows that if one object of an equal-weight pair were consistently lifted through a longer lever system, that object would be expected to feel heavier.

In the size-weight illusion where objects differ in size

\footnotetext{
*This research was supported by Simon Fraser University President's Research Grant 709-030.
}

but not in weight, it may be that the smaller object is supported further distally than the larger one. Indeed, the DeMoors size-weight illusion cans (Marrietta Apparatus Co., Catalog No. 68A-18-6) in our laboratory are constructed in a fashion that encourages just such leverage bias. The wire handles of the $450 \mathrm{~g}$ cans project from the rim of the cans, forming rectangular openings of different widths: $6.4 \mathrm{~cm}$ on the small can and $9.0 \mathrm{~cm}$ on the large can of the set in our laboratory. The $9.0-\mathrm{cm}$ width allows most hands to pass through the handle up to the base of the thumb, while the $6.4 \mathrm{~cm}$ width accommodates no more than three fingers. As a result, the cans may tend to be lifted in the manner shown in Fig. 1, the small can by the fingertips, the large one from near the palm.

Untrained Os often lift the cans in the manner shown in Fig. 1, though not always with so large a difference. Of 60 university students who lifted the two cans singly, palm up, without further instruction, 28 lifted the small can through an observably longer lever, while the reverse was true in only five cases; the difference was significant $(p<.001)$ by a chi-square test. More generally, it is likely that large objects are lifted through shorter levers than are small objects whenever possible.

The effect of lever length on the SWI should be demonstrated by carefully lifting the cans both through the same lever system and again with the mechanical advantage favoring the small can. That is, by lifting the large can by the fingertips and the small one from the base of the fingers. In the latter case, the prediction would be that the size-weight illusion would occur less frequently and that the reverse illusion might be created; the large can may feel heavier than the small one.

Eighteen Ss lifted the two cans in pairs four times, twice through equal levers and twice through unequal levers. Ss were seated and their right arms taped to the chair arm just proximal to the wrist, palm up. The cans were on a rotatable circular table in front of the chair arm, allowing the cans to be moved to position near the protruding hand. Ss were to lift each can and replace it in a smooth motion when instructed. The lifting 

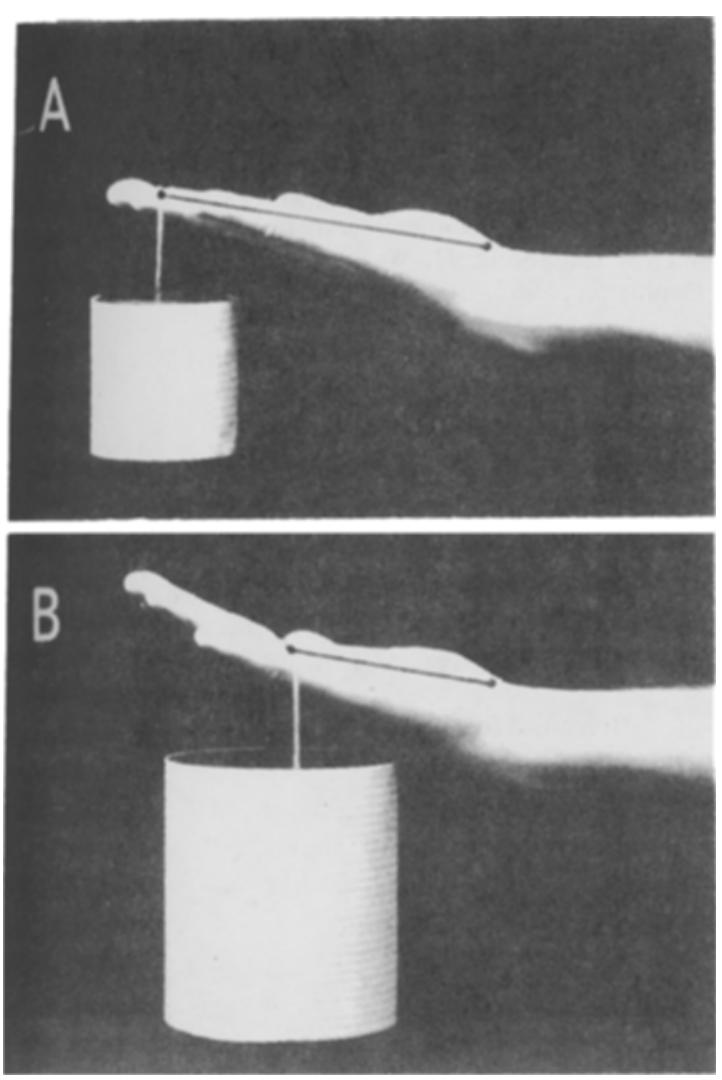

Fig. 1. DeMoors size-weight illusion cans, small can supported near fingertips (A) and large can at the base of the fingers (B).

movement and the procedure were practiced using a dummy can. Ss were further instructed to report which can felt heavier or whether the two cans felt equally heavy after the second can of a pair had been replaced. On equal-leverage trials, the handles of both cans were placed across the palmar surface of the terminal phalanx of the first three fingers. On unequal-leverage trials, the small can was placed at the base of the first three fingers (with the little finger oritside the handle) and the large can was placed as in equal-leverage trials (Fig. 2). Equal and unequal leverage trials were alternated. Half of the Ss experienced equal levers on the first trial. The interlift and intertrial intervals were 10 and $40 \mathrm{sec}$, respectively.

The SWI was present on $91 \%$ of the equal-leverage trials and absent on the remaining $9 \%$. The large can'was never felt to be heavier than the small one. However. when the mechanical advantage favored the small can, there was a shift of judgments away from the SWI. The SWI was still present on $27 \%$ of the trials: the cans felt equally heavy on $25 \%$. On $28 \%$ of the trials, the SWI was reversed; the large can felt heavier than the small one. The shift away from the SWI was significant $(p<.025)$ by a test of the significance of differences between observed proportions (for this analysis, $N=18$, and S's two judgments contributed one unit to the proportion) (Natrelia. i963).

The results of the second experiment allow two conclusions. First, mechanical advantage can influence weight judgments. The significant shift in judgments toward reporting the large can to be the heavier is quite convincing. I have been experimenting with the illusion for more than 3 years, and during that time the illusion has faded from time to time, but the large can has never felt heavier than the small one. Second, mechanical advantage cannot be said to be of primary importance in producing the illusion, at least not in the controlled lifting situation employed here. With mechanical advantage equal in both lifts, the SWI was present $91 \%$ of the time. Other factors are clearly acting to produce the illusion. However, the two experiments taken together suggest that mechanical advantage may bias judgments in the direction of producing or magnifying the SWI when lever length is uncontrolled.

The mechanical advantage effect may explain van Biervliet's demonstration described by Koseloff (1957), in which a bottle felt heavier when lifted by the neck than when it was lifted from the bottom. Koseloff felt that such a demonstration was evidence for a phenomenological explanation of the SWI: "... van Biervliet's experiment where 0 lifts a bottle by the neck or by the bottom complicates our picture of the SWE, as the 'size' which lends its name to the

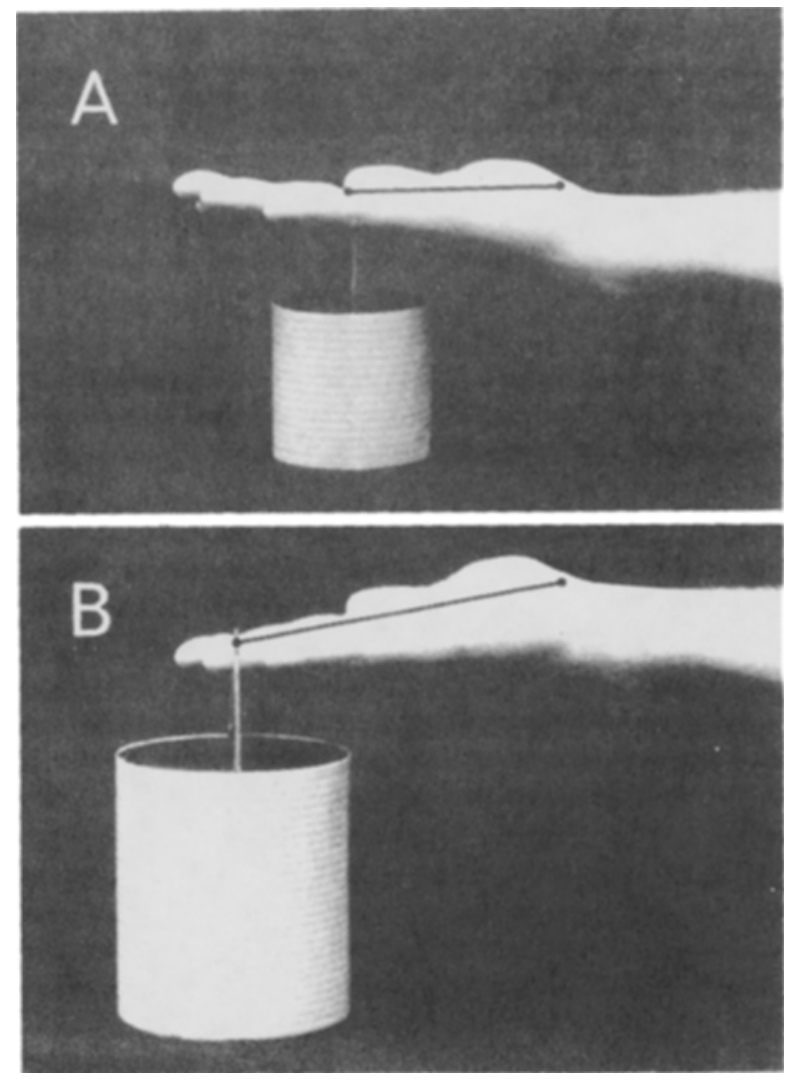

Fig. 2. DeMoors size-weight illusion cans. small can lifted from the fingertips (A) and large can from near the base of the fingers (B). 
'size-weight-effect' is the same in the two situations that are compared. So it is not the difference between the physical volumes of the objects which is a necessary condition for the SWE [Koseloff, 1957, p. 250]." While that observation is accurate, it is not complete; even though the lifting situation is more complex than in the experiments reported here, there are apparent differences in mechanical advantage when a bottle is lifted as described. When lifted from the bottom, the center of mass of a bottle is usually near the middle of the palm, a shorter lever than that formed when the bottle is grasped at the neck between thumb and forefinger. Though mechanical advantage may not explain the "bottle illusion," it is present and points out the necessity to consider mechanics where weight comparisons are studied.

\section{REFERENCES}

Koseloff, P. Studies in the perception of heaviness I. Acta
Psychologica, 1957, 13, 242-252.

Morgan, J. Introduction to university physics. Boston: Allyn \& Bacon, 1963. P. 218.

Müller, G. E., \& Schumann, Fr. Über die psychologischen Grundlagen der Vergleichung gehobener Gewichte. Archiv für die gesamte Physiologie, 1889, 45, 37-112.

Natrella, M. G. Experimental statistics. National Bureau of Standards Handbook 91. Washington, D.C: U.S. Department of Commerce, 1963.

\section{NOTE}

1. The mass of the physiological lever is properly a factor in this analysis. For the results to be quantitatively correct, the presence of hand mass and its distribution would need to be accounted for. While this would alter the numerical result, it would not change the direction of the mechanical advantage.

(Received for publication December 1971; revision received November 1,1972 .) 